\title{
In vitro and in vivo effects of rat kidney vascular endothelial cells on osteogenesis of rat bone marrow mesenchymal stem cells growing on polylactide-glycoli acid (PLGA) scaffolds Hongchen Sun*1, Zhe $\mathrm{Qu}^{\dagger 2}$, Ying $\mathrm{GuO}^{2}$, Guangxiang Zang ${ }^{1}$ and Bai Yang ${ }^{3}$
}

Address: ${ }^{1}$ Department of Oral Pathology, School of Stomatology, JiLin University, ChangChun, 130041, P. R. China, ${ }^{2}$ Department of Oral and Maxillofacial Surgery, Dalian Stomatological Hospital, Dalian, 116021, P. R. China and ${ }^{3}$ Key Lab for Supramolecular Structure and Materials of Ministry of Education, College of Chemistry, Jilin University, Changchun, 130012, P. R. China

Email: Hongchen Sun* - hcsun@jlu.edu.cn; Zhe Qu - quzhekq@hotmail.com; Ying Guo - guohining@hotmail.com; Guangxiang Zang - zenggx@hotmail.com; Bai Yang - yangbai@jlu.edu.cn

* Corresponding author †Equal contributors

Published: 4 November 2007

BioMedical Engineering OnLine 2007, 6:4I doi:I0.1 I86/I475-925X-6-4I
Received: 15 April 2007

Accepted: 4 November 2007

This article is available from: http://www.biomedical-engineering-online.com/content/6/l/4I

(C) 2007 Sun et al; licensee BioMed Central Ltd.

This is an Open Access article distributed under the terms of the Creative Commons Attribution License (http://creativecommons.org/licenses/by/2.0), which permits unrestricted use, distribution, and reproduction in any medium, provided the original work is properly cited.

\begin{abstract}
It is well established that vascularization is critical for osteogenesis. However, adequate vascularization also remains one of the major challenges in tissue engineering of bone. This problem is further accentuated in regeneration of large volume of tissue. Although a complex process, vascularization involves reciprocal regulation and functional interaction between endothelial and osteoblast-like cells during osteogenesis. This prompted us to investigate the possibility of producing bone tissue both in vitro and ectopically in vivo using vascular endothelial cells because we hypothesized that the direct contact or interaction between vascular endothelial cells and bone marrow mesenchymal stem cells are of benefit to osteogenesis in vitro and in vivo. For that purpose we co-cultured rat bone marrow mesenchymal stem cells (MSC) and kidney vascular endothelial cells (VEC) with polylactide-glycolic acid scaffolds. In vitro experiments using alkaline phosphatase and osteocalcin assays demonstrated the proliferation and differentiation of MSC into osteoblast-like cells, especially the direct contact between VEC and MSC. In addition, histochemical analysis with $C D 3$ I and von-Willebrand factor staining showed that VEC retained their endothelial characteristics. In vivo implantation of MSC and VEC co-cultures into rat's muscle resulted in prevascular network-like structure established by the VEC in the PLGA. These structures developed into vascularized tissue, and increased the amount and size of the new bone compared to the control group $(p<0.05)$. These results suggest that the vascular endothelial cells could efficiently stimulate the in vitro proliferation and differentiation of osteoblast-like cells and promote osteogenesis in vivo by the direct contact or interaction with the MSC. This technique for optimal regeneration of bone should be further investigated.
\end{abstract}

\section{Introduction}

Bone deficiency following trauma, resection of tumour, periodontal disease or congenital malformation can be associated with functional and aesthetic problems. To address these issues and to improve patients' well-being bone tissue engineering has been proposed [1-4]. Tissue engineering techniques have mainly been applied on avascular tissue or on other tissue that can grow without 
an additional vascular supply, such as epithelia, cartilage or large vessel substitutes $[5,6]$. However, one of the major challenges in regeneration of bone tissue is its vascularization because the center necrosis of the engineered bone tissue will occur if blood supply (nutrition and oxygen) cannot be established quickly [7]. Since diffusion of oxygen in the active tissue is limited about $150 \mu \mathrm{m}$ from capillary (mean of intercapillary distance (ICD) was $304 \pm 30$ $\mu \mathrm{m}$.)[8], vascularization becomes crucial in larger volume of tissue-engineered construct. Growth factors, such as vascular endothelial growth factor (VEGF), collagen type II, myometrial prostaglandin E2, epithelial growth factor and basic fibroblast growth factor (bFGF), have been widely used to accelerate neovascularization in order to regenerate damaged tissues $[9,10]$. Previously, in vivo secondary vascularization of engineered tissue was attempted with partial success [11]. Alternatively, in vitro construction of vascular stroma could serve as a scaffold for soft or hard-tissue transplant.

Reciprocal regulation and functional interaction between endothelial and osteoblast-like cells during osteogenesis has been reported [1-4,11,12]. Villars et al suggested that membrane proteins as well as systemic hormones and growth factors have an active role in this process [12]. Therefore, to transplant large volume of engineered bone tissue successfully, vascularized bone tissue with the endothelial cells in three-dimensional scaffold in vitro could be used [13]. This may not only solve the nutrition and oxygen diffusion to the middle of the bone tissue [14], but also stimulate osteogenesis by the endothelial cells.

Although some of previous studies showed that vascular endothelial cells and growth factors of vascular endothelial cells could play a role in osteogenesis, it still didn't document well if the direct contact or interaction could be the best way to stimulate osteogenesis, especially in vivo. We hypothesized that the direct contact or interaction between vascular endothelial cells and bone marrow mesenchymal stem cells could be an optimal way to stimulate osteogenesis in vitro and in vivo. Therefore, our objective of present studies was to know what kind of interaction the vascular endothelial cells could efficiently stimulate osteogenesis in vitro and in vivo. To achieve our objective, rat kidney vascular endothelial cells (VEC) and bone marrow mesenchymal stem cells (MSC) were cultured together or alone on PLGA scaffold. The in vitro effect of endothelial cells on osteogenesis by MSC was evaluated. Additionally, MSC-plated PLGA or MSC and VEC-plated PLGA were implanted into the rat's thigh and bone formation was evaluated by soft X-ray analysis and histologically. Our results demonstrated the dramatically effects on osteogenesis in vitro and in vivo while the vascular endothelial cells directly contacted or interacted with the bone marrow mesenchymal stem cells on PLGA scaffold.

\section{Materials and methods}

\section{Isolation and culture of rat MSC and VEC}

Animal experiments were approved by the Animal Care and Use Committee of Jilin University. Male Wistar rats (250 - 350 g, 6-8 weeks old) were anesthetized with intramuscular administration of ketamine $(60 \mathrm{mg} / \mathrm{kg})$ and xylazine $(8 \mathrm{mg} / \mathrm{kg})$. Bone marrow mesenchymal stem cells were sterilely harvested from the femur and grown in 199 medium supplemented with $10^{-6} \mathrm{M}$ desacortone, 50 $\mu \mathrm{g} / \mathrm{ml}$ ascorbic acid (Invitrogen), 1\% L-glutamine, 10\% fetal bovine serum (Invitrogen), $100 \mathrm{U} / \mathrm{ml}$ penicillin G (Invitrogen), $100 \mu \mathrm{g} / \mathrm{ml}$ streptomycin (Invitrogene, Carlsbad, CA, USA). Osteogenetic potential and calcium precipitation were evaluated by alkaline phosphatase (ALP)[15] and von Kossa [13] staining, respectively. Rats' kidneys were harvested, rinsed with PBS, and their cortex dissected and sliced to 1-2 mm pieces. The tissue was then digested for 2 hours with $0.25 \%$ collagenase (type II, Sigma, St. Louis, MO, USA). Disperesed kidney vascular endothelial cells (VEC) were collected and cultured in endothelial growth medium (Technoclone, Austria). CD31 and von-Willebrand factors staining were performed using the ImmunoCruz Staining System (Santa Cruz Biotechnology, Inc., Santa Cruz, CA, USA)[16]. All cultures were grown at $37^{\circ} \mathrm{C}$ in a humidified $5 \% \mathrm{CO}_{2}$ atmosphere. After the second passage cells were observed with transmission electron microscopy (HITACHI, Japan)[17].

\section{Fabrication of Scaffold}

Polylactide-glycolic acid (PLGA) was synthesized using a similar approach described by previous reports [18-20]. Briefly, 85:15 (mol:mol) copolymer of D,L-lactide and glycolide (PLG) was milled and sieved to particles ranging from 106 to $250 \mu \mathrm{m}$. The PLGA particles were mixed with $5 \mathrm{~g} \mathrm{NaCl}$ and molded to form a disc $(1 \mathrm{~cm} \times 1 \mathrm{~cm} \times 0.5$ $\mathrm{cm}$ ) which was pressured at $800 \mathrm{~Pa}$ and under $\mathrm{CO}_{2}$ to form an interconnected polymer network. The disc was immersed in $\mathrm{dd}_{2} \mathrm{O}$ for 24 hour to leach $\mathrm{NaCl}$ which resulted in a $95 \%$ porus scaffold with $25-400 \mu \mathrm{m}$ pores. The disc was sterilized with gamma irradiation (Co-60) without effects of physical and chemical characteristics.

\section{In vitro three-dimensional co-culture models}

MSC and VEC were cultured either with direct contact, indirect contact, or separately. (1) In the direct contact setup MSC and VEC ( $10^{4}$ cells/well) were plated on a prewetted PLGA disc in a 24-well plate. Two hours later growth medium was added onto the cells. (2) In the indirect contact setup MSC were cultured for 12 hours on prewetted PLGA disc as described and then moved onto cultured VEC in 24-well plates. (3) In the third setup MSC 
and VEC were cultured separately onto PLGA discs as described above [21]. All cultures were grown for 5 days with daily medium changes and then supernatant and cells were harvested for osteocalcin and ALP assays. Protein was quantitated using BCA protein assay kit (Pierce, USA).

\section{In vivo rat's thigh model}

Male Wistar rats (250 - 350 g, 6-8 weeks old) were anesthetized and their bilateral thigh areas were disinfected and incised to expose and separate muscle fibers. PLGA plated with either MSC and VEC or MSC alone and cultured for 2 days were implanted into the right and left thigh muscles, respectively. Skin incisions were sutured and animals were administered a daily intramuscular injection of Benzylpenicillin (10,000 U/day). 8 or 12 weeks following surgery the implants were harvested and subjected to soft X-ray examination and subsequent image analysis (NIH image software, National Institutes of Health, USA) for determination of osteogeneic activity. In addition, samples were stained with hematoxylin \& eosin and evaluated histologically.

\section{Determination of ALP activity and osteocalcin synthesis} The ALP activity was determined using alkaline phosphatase detection kit (Sigma, St. Louis, MO, USA)[13]. Data were expressed as a ratio of unit (U) inorganic phosphate $(\mathrm{Pi})$ enzymatically-cleaved in $30 \mathrm{~min} / \mathrm{mg}$ protein. Osteocalcin synthesis was determined using osteocalcin radioactivity kit (Biosource, Germany)[19].

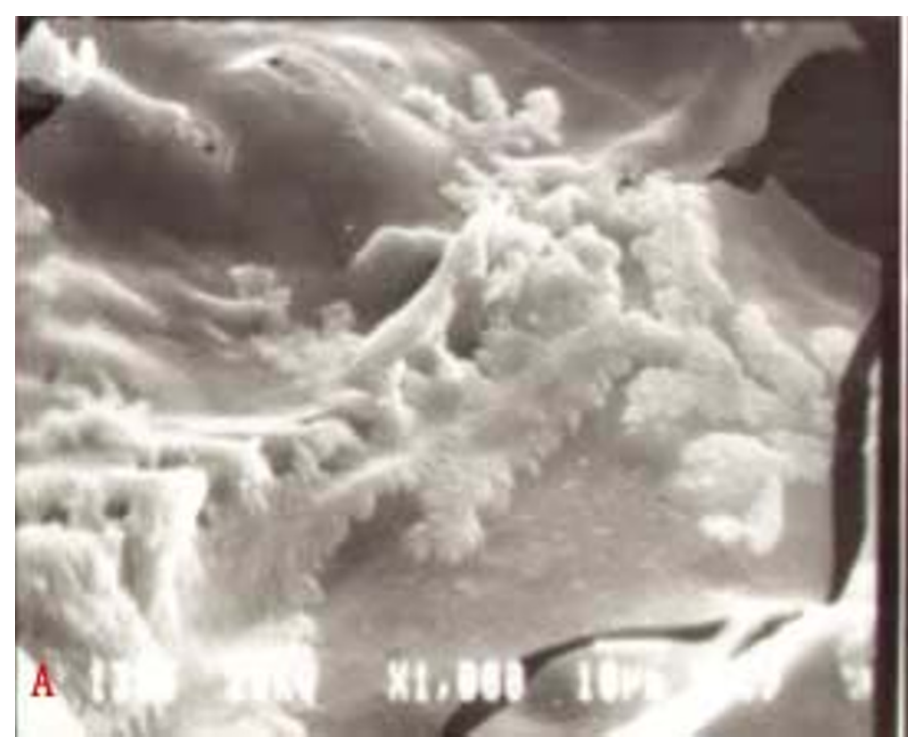

\section{Statistical analysis}

All experiments were repeated 6 times. Data were analysed with student $t$-test and multiple range test (SPSS 11.5, Chicago, USA) and presented as mean \pm standard deviation (SD). Differences were considered significant when $p$ $<0.05$.

\section{Results \\ Evaluation of MSC and VEC cultures}

In the presence of desacortone and ascorbic acid and after 3 passages the morphology of MSC changed from fusiform monolayer to multilateral shaped, multilayer small colonies. The cells demonstrated even higher proliferation rate after 4 or 5 passages. After 7 days, a ALP-positive black zone could be seen around the cells and von-Kossa-positive calcium deposition was noted. These results indicate that MSC posses osteoblast-like characteristics. VEC were CD31 and von-Willebrand-positive and had a round and oval (stone-like) morphology arranged as a road array (data not shown).

\section{In vitro effect of VECs on MSCs osteogenic potential in the three-dimensional co-culture}

Five days after culturing MSC and VEC on PLGA the discs were examined by scanning electron microscopy and the results are presented in figure 1. MSC could be seen adhered and extended on the PLGA surface with pseudopodium present between the cells (Fig. 1A). Oval and stone-like shaped VEC forming prevascular network-like structures were also seen on the PLGA surface (Fig. 1B). The osteogenic potential of the 3 culture setups on PLGA

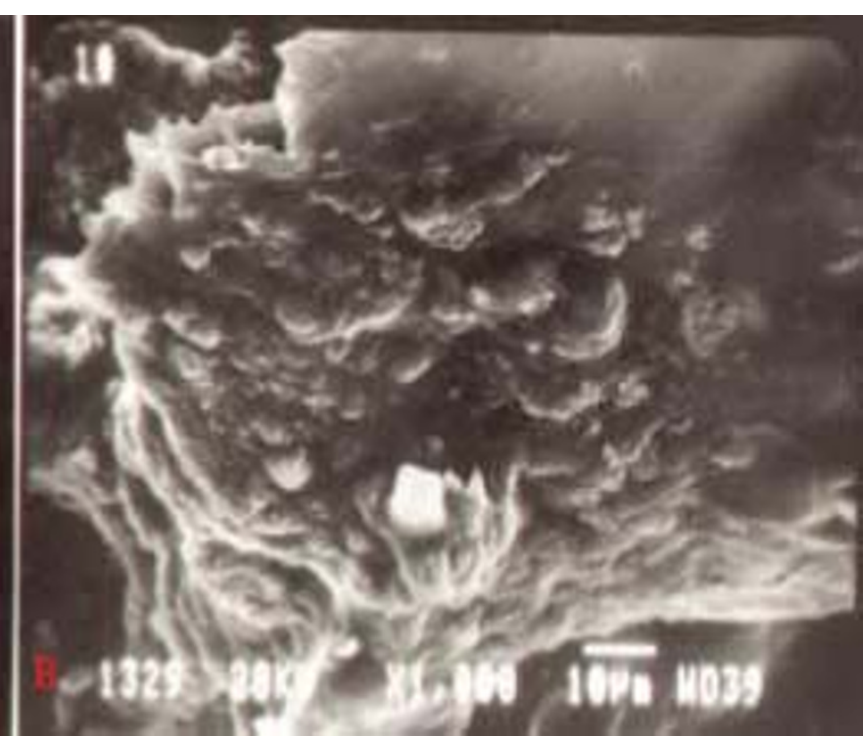

\section{Figure I}

Image of the MSCs and VECs on the PLGA surface from scanning electron microscopy. A. MSCs adhere and extend on the PLGA surface. The arrow indicates the pseudopodium $(\times 1000)$. B. VECs adhere on the PLGA surface as an oval and stone-like shape $(\times 1000)$. 
was measured using ALP activity and osteocalcin synthesis and the results are displayed in figure 2. Cultured MSC had low ALP activity of $0.15 \pm 0.02$ whereas indirect-contract co-cultures of MSC and VEC had a higher activity of $0.44 \pm 0.05$. Significant $(\mathrm{p}<0.05)$ increase in ALP activity $(0.65 \pm 0.04 \mathrm{U} / \mathrm{mg}$ protein $)$ was seen in direct contact cocultured MSC and VEC setup (Fig. 2A). Synthesis of osteocalcin (a specific marker of bone cells) showed similar results to those of ALP and are shown in Figure 2B. Direct contact co-cultures of MSC and VEC had a significantly ( $\mathrm{p}$ $<0.05$ ) higher levels of osteocalcin when compared to cultured MSC. The rank order for osteocalcin synthesis was direct contact $>$ indirect contract $>$ MSC. The data indicate that in vitro direct contact between MSC and VEC induced osteogeneis.
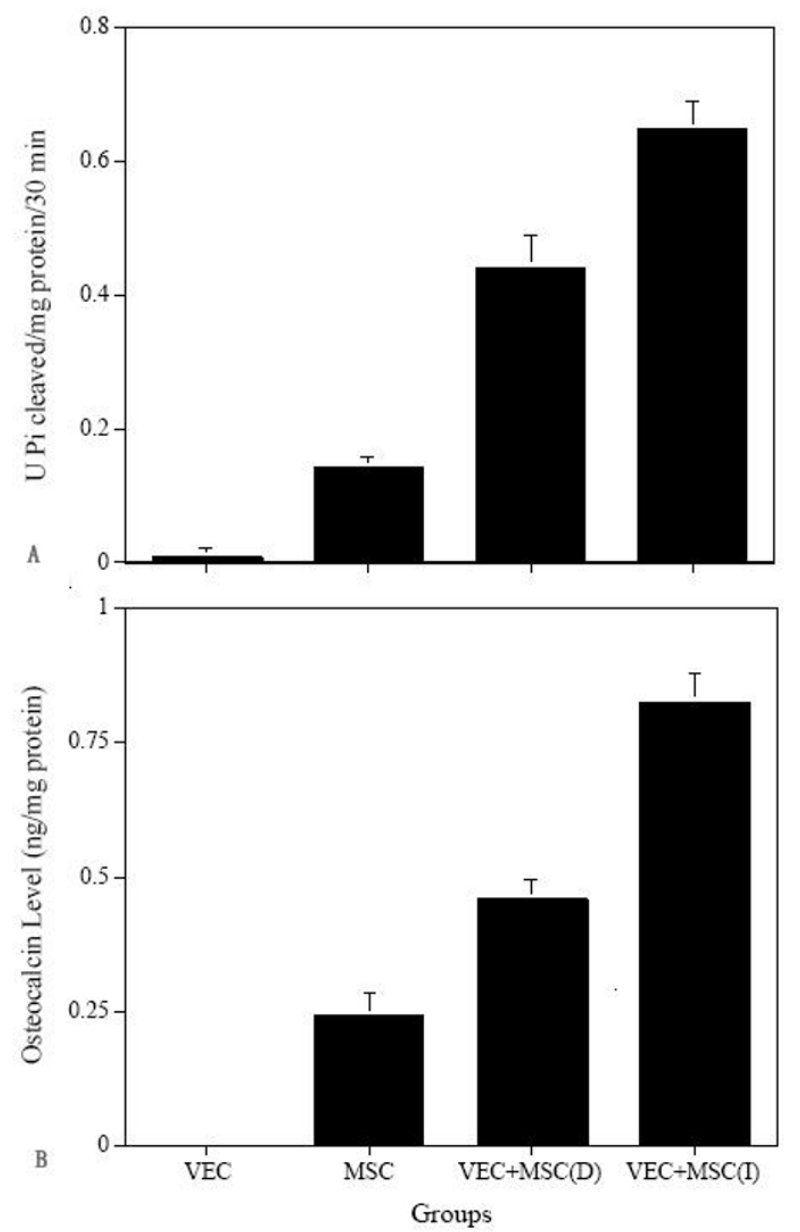

Figure 2

ALP activity and osteocalcin synthesis from three-dimensional co-culture in vitro. A. The ALP activity. B. Osteocalcin synthesis. The data shown are the means \pm SD from six experiments. (I) means indirect. (D) means direct.

\section{In vivo effect of VECs on MSC osteogenic potential}

After 8 or 12 weeks following implantation specimens were collected and examined by soft X-rays. The corresponding radiographs are shown in figure 3. Eight weeks post-implantation, diffuse radio-opacity could be seen in the right thigh but not in the left (data not shown). This difference between the right thigh (with the MSC and VEC plated PLGA) and the left thigh (with the MSC plated PLGA) was even more pronounced at 12 weeks after the implantation (Fig. 3A and 3B). Densitometry of the various samples was performed using the NIH-image software and the results are displayed in figure 4 . While the left thigh was no different from control, a 2-fold increase in density was seen in the right thigh (Fig. 3C). These results
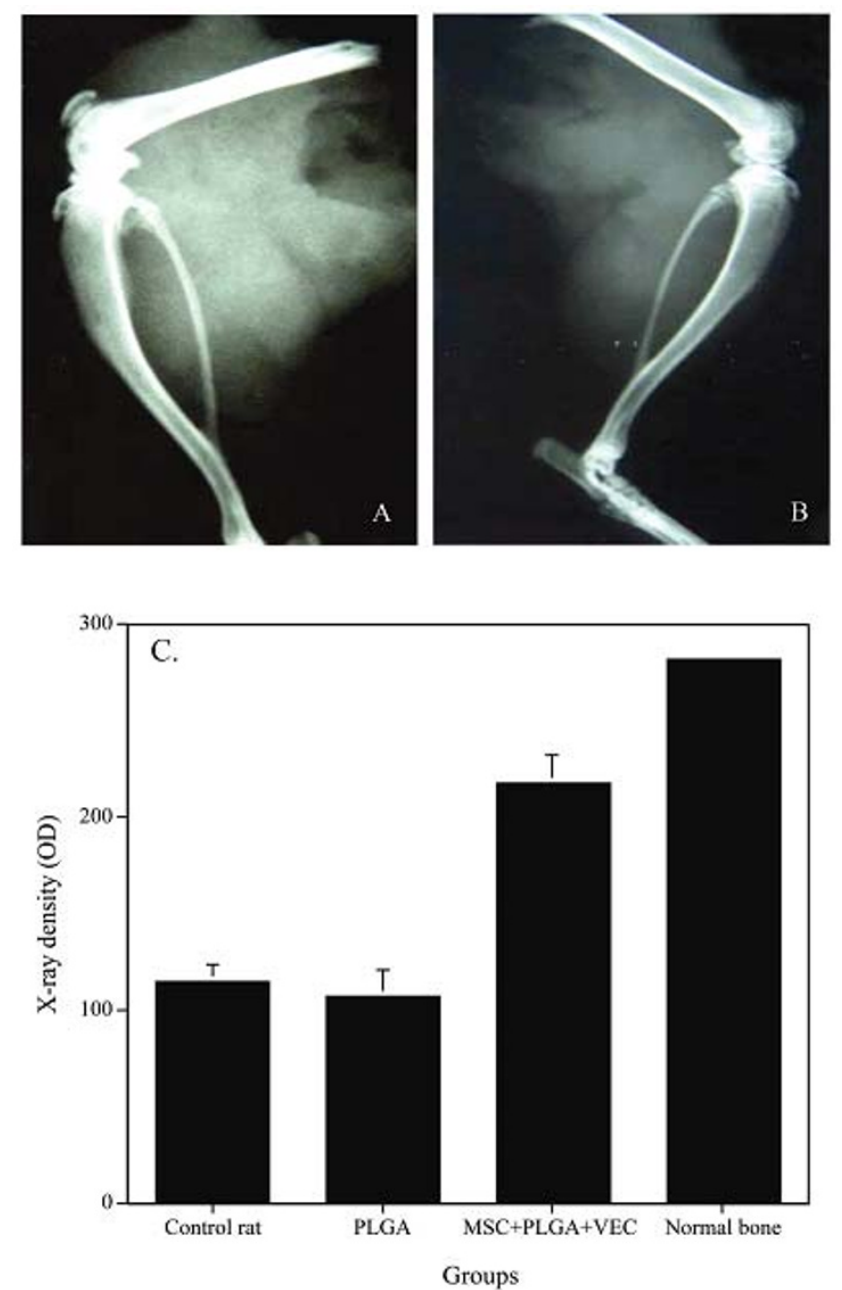

Figure 3

Soft X-ray images from right and left thigh and X-ray density analysis using NIH image software. A. Right thigh implanted with the PLGA seeded with the MSCs and VECs. B. Left thigh implanted with the PLGA seeded with the MSCs. C. X-ray density analysis. The data shown are the means \pm SD from six experiments. 

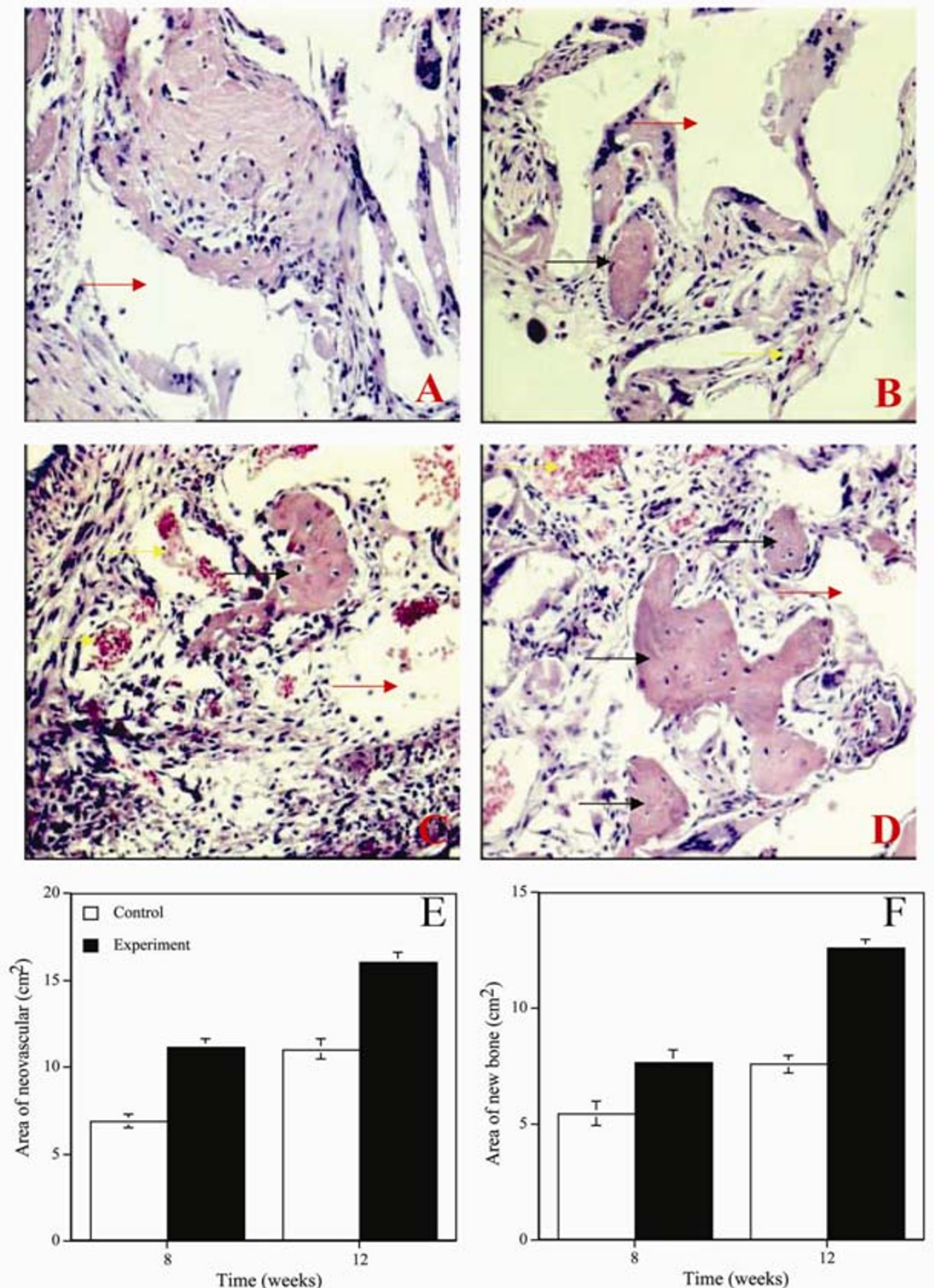

\section{Figure 4}

Hematoxylin and eosin staining of the implanted area from rat thigh and Quantitative measurements of new blood vessel and new bone from HE staining slides. A. Control group at 8 weeks post-implanted. B. Experiment group at 8 weeks postimplanted. C. Control group at 12 weeks post-implanted. D. Experiment group at I 2 weeks post-implanted. Control is left thigh implanted with the PLGA seeded with the MSCs. Experiment is right thigh implanted with the PLGA seeded with the MSCs and VECs. Red arrow indicates PLGA material. Black arrow indicates new bone. Yellow arrow indicates blood vessel. E. New blood vessel. F. New bone. Control is left thigh implanted with the PLGA seeded with the MSCs. Experiment is right thigh implanted with the PLGA seeded with the MSCs and VECs. The data shown are the means \pm SD from six experiments. 
suggest that addition of VEC to cultured MSC induced osteogenesis in vivo.

Following soft X-ray analysis the samples were fixed in formalin and stained with hematoxylin \& eosin. Typical histological pictures are presented in figure 4 . Eight weeks after implantation, new bone tissue could be seen both in the left (Fig. 4A) and right (Fig. 4B) thighs. Four weeks later, new blood vessels were also found in both thighs. Histomorphometry of newly formed bone and blood vessels was also performed and the results are shown in figure $4 \mathrm{E}$ and $4 \mathrm{~F}$. Eight and 12 weeks after implantation, a significant $(\mathrm{p}<0.05)$ increase both in neovasculature and bone formation could be seen in the right thigh (implanted with MSC and VEC-plated PLGA) when compared to the left thigh (implanted with MSC-plated VEC).

\section{Discussion}

Angiogenesis, the development of vascular network, is essential for tissue growth and repair including bone $[22,23]$. Vascularization of implanted bone tissue can occur by in-growth of host blood vessels or to originate within the implanted bone tissue. In-growth of new blood vessels from the host progresses at a slow rate which is inadequate for large volumes of bone tissue. Regenerated bone containing potential blood vessel elements or blood vessel-like structures can facilitate the vascularization process [24,25]. These elements in tissue-engineered implants could be critical to their survival [22].

In the present study, we have demonstrated the use of direct contact or interaction between MSC and VEC for formation of vascularised bone tissue in vivo. Previously [26], we have shown that VEC could be successfully enriched under specific conditions. CD31- and von-Willebrand factor-positive VEC (data not shown) were cultured on PLGA discs. These VEC formed pre-vascular network-like structure on the surface of the PLGA (Fig. 1) and were also osteocalcin-negative and had very low ALP activity (Fig. 2). MSC are a good source for osteoprogenitors cells or osteostem cells which can differentiate to chrondogenic and osteogenic cells [27]. In vitro cultures of MSC-plated PLGA had low levels of ALP activity and of osteocalcin (Fig. 2). Addition of VEC either indirectly or directly, especially directly, to the MSC-plated PLGA increased the osteocalcin and ALP activity levels substantially (Fig. 2). In vitro direct contact of the MSC and VEC enhanced 3.4 fold osteogenesis compared to MSC alone. These results indicated that the differentiation of MSC could be regulated not only by cytokines, but also by cell direct contact [12].

In vivo experiments demonstrated that MSC-plated PLGA implanted in the thigh muscle of the rat induced formation of new bone and blood vessels as seen in histological evaluation (Fig. 4). This newly formed bone could not be detected in soft X-ray analysis (Fig. 3). MSC and VECplated PLGA implanted in the rat's thigh led to substantially more vascularized bone tissue being formed (Fig. 4). In the case of MSC and VEC-plated PLGA newly formed bone could be seen in soft X-ray analysis (Fig. 3). The interaction of MSC and VEC is probably essential, complex and mutual since both new blood vessels and bone were generated. This effect of the MSC on the VEC is in accord with previous report which showed that hMSC could also secrete growth factors which stimulated endothelial cell proliferation [28-30].

In conclusion, our results demonstrate that VEC can enhance vascularization in engineered-bone tissue by the direct contact or interaction with MSC in the rat in vivo. This technique could be useful in repairing damaged bone tissue.

\section{Acknowledgements}

This study was supported by National Natural Science Foundation of China grand 3047/893. We are most appreciative of the critical comments on an earlier draft of the manuscript by, and helpful suggestions of Dr. Changyu Zheng (NIDCR, NIH).

\section{References}

I. Rouwkema J, de Boer J, Van Blitterswijk CA: Endothelial cells assemble into a 3-dimensional prevascular network in a bone tissue engineering construct. Tissue Eng 2006, I 2:2685-2693.

2. Hausman MR, Schaffler MB, Majeska RJ: Prevention of fracture healing in rats by an inhibitore of angiogenesis. Bone 200I, 29:560-564.

3. Akita $\mathrm{S}$, Yoshikawa $\mathrm{H}$, Hashimoto J, Ueda T, Funai $\mathrm{H}$, Kato $\mathrm{M}$, Yoshikawa $\mathrm{H}$ : Capillary vessel network integration by inserting a vascular pedicle enhances bone formation in tissueengineered bone using interconnected porous hydroxyapatite cremics. Tissue Eng 2004, 10:789-795.

4. Kim WS, Kim HK: Tissue engineered vascularized bone formation using in vivo implanted osteoblast-polyglycolic acid scaffold. J Korean Med Sci 2005, 20:479-482.

5. Zwaginga J, Doevendans P: Stem cell-derived angiogenic/vasculogenic cells: Possible therapies for tissue repair and tissue engineering. Clin Exp Pharmacol and Physiol 2003, 30:900-908.

6. Sodian R, Hoerstrup SP, Sperling JS, Daebritz SH, Martin DP, Schoen FJ, Vacanti JP, Mayer Jr: Tissue engineering of heart valves: in vitro experiences. Ann Thorac Surg 2002, 70: I 140-I 44.

7. Ochoa ER, Vacanti JP: An overview of the pathology and approaches to tissue engineering. Ann NY Acad Sci 2002, 979:10-26.

8. Awwad HK, el Naggar M, Mocktar N, Barsoum M: Intercapillary distance measurement as an indicator of hypoxia in carcinoma of the cervix uteri. Int J Radiat Oncol Biol Phys 1986, I 2:1329-1333.

9. Orban JM, Marra KG, Hollinger JO: Composition options for tissue-engineered bone. Tissue Eng 2002, 8:529-539.

10. Murphy WL, Peters MC, Kohn DH, Mooney DJ: Sustained release of vascular endothelial growth factor from mineralized poly(lactide-co-glycolide) scaffolds for tissue engineering. Biomaterials 2000, 21 : 2521-2527.

II. Vacanti CA, Kim W, Upton J, Vacanti MP, Mooney D, Schloo B, Vacanti JP: Tissue-engineered growth of bone and cartilage. Transplant Proc 1993, 25:1019-1021.

12. Villars F, Bordenave L, Bareille R, Amedee J: Effect of human endothelial cells on human bone marrow stromal cell phenotype: role of VEGF? J Cell Biochem 2000, 79:672-685. 
13. Frerich B, Lindemann N, Kurtz-Hoffmann J, Oertel K: In vitro model of a vascular stroma for the engineering of vascularized tissues. Int J Oral Maxillofac Surg 200I, 30:4I4-420.

14. Tiwari A, Salacinski HJ, Hamilton G, Seifalian AM: Tissue Engineering of Vascular Bypass Grafts: Role of Endothelial Cell Extraction. European Journal of Vascular and Endovascular Surgery 200I, 2 I: |93-20|.

15. Hiltunen MO, Ruuskanen M, Huuskonen J, Mahonen AJ, Ahonen M, Rutanen J, Kosma VM, Mahonen A, Kroger H, Yla-Herttuala S: Adenovirus-mediated VEGF-A gene transfer induces bone formation in vivo. FASEB J 2003, I 7: I |47- I |49.

16. Pusztaszeri MP, Seelentag W, Bosman FT: Immunohistochemical expression of endothelial markers CD3 I, CD34, vonWillebrand factor, and Fli-I in normal human tissues. J of Histochem and Cytochem 2006, 54:385-395.

17. Collin-Osdoby P: Role of vascular endothelial cells in bone biology. J Cell Biochem 1994, 55:304-309.

18. Athanasiou KA, Niederauer GG, Agrawal CM: Sterilization, toxicity, biocompatibility and clinical applications of polylactic acid/polyglycolic acid copolymers. Biomaterials 1996, I 7:93-102.

19. Agrawal CM, Athanasiou KA: Technique to control pH in vicinity of biodegrading PLA-PGA implants. J Biomed Mater Res 1997, 38: $105-1 \mid 4$

20. Shearer H, Ellis MJ, Perera SP, Chaudhuri JB: Effects of Common Sterilization Methods on the Structure and Properties of Poly(D,L Lactic-Co-Glycolic Acid) Scaffolds. Tissue Eng 2006, I 2:27|7-272|

21. Villars F, Guillotin B, Amedee T, Dutoya S, Bordenave L, Bareille R, Amedee J: Effect of HUVEC on human osteoprogenitor cell differentiation needs heterotypic gap junction communication. Am J Physiol Cell Physiol 2002, 282:C775-785.

22. Murphy WL, Kohn DH, Mooney DJ, Peters MC: Sustained release of vascular endothelial growth factor from mineralizedpoly (lactide-co-glycolide) scaffolds for tissue engineering. Biomaterials 2000, 21 :2521-2527.

23. Winet $\mathrm{H}$ : The role of microvasculature in normal and perturbed bone healing as revealed by intravital microscopy. Bone 1996, 19:39S-57S.

24. Rohner D, Tan B, Song C: Repair of composite zygomaticomaxillary defects with free bone grafts and free vascularized tissue transfer. J Craniomaxillofac Surg 2001, 29:337-343.

25. Fureder W, Krauth MT, Sperr WR, Sonneck K, Simonitsch Klupp I, Mullauer L, Willmann M, Horny HP, Valent P: Evaluation of angiogenesis and vascular endothelial growth factor expression in the bone marrow of patients with aplastic anemia. Am J of Pathol 2006, 168: I 23-130

26. Qu Z, Sun H, Guo Y, Zhang Z, Yang R, Jie Q: The Influence of ossicication abilrt of the messenchlymal stem cells co-cultured with vascular endothelial cell in vitro. J Comprehensive Stomatol (Chinese) 2003, 19:480-488.

27. Pittenger MF, Mackay AM, Beck SC, Jaiswal RK, Douglas R, Mosca JD, Moorman MA, Simonetti DW, Craig S, Marshak DR: Multilineage potential of adult human mesenchymal stem cells. Science 1999, 284: |43-|47.

28. Kaigler D, Krebsbach PH, Polverini PJ, Mooney DJ: Role of vascular endothelial growth factor in bone marrow stromal cell modulation of endothelial cells. Tissue Eng 2003, 9:95-103.

29. Furumatsu T, Shen ZN, Kawai A, Nishida K, Manabe H, Oohashi T, Inoue $\mathrm{H}$, Ninomiya $\mathrm{Y}$ : Vascular endothelial growth factor principally acts as the main angiogenic factor in the early stage of human osteoblastogenesis. J Biochem (Tokyo) 2003, 133:633-639.

30. Spector JA, Mehrara BJ: Osteoblast expression of vascular endothelial growth factor is modulated by the extracellular microenvironment. J of Physiol Cell Physiol 200I, 280:C72-80.
Publish with Bio Med Central and every scientist can read your work free of charge

"BioMed Central will be the most significant development for disseminating the results of biomedical research in our lifetime. "

Sir Paul Nurse, Cancer Research UK

Your research papers will be:

- available free of charge to the entire biomedical community

- peer reviewed and published immediately upon acceptance

- cited in PubMed and archived on PubMed Central

- yours - you keep the copyright

Submit your manuscript here:

http://www.biomedcentral.com/info/publishing_adv.asp
BioMedcentral 